\title{
Comentário de Decisão \\ Homologação do Ato Administrativo \\ Estrangeiro Equiparado a Sentença \\ Estrangeira $^{1}$
}

\section{Tomoko Kimura Gaudioso \\ Professora do Instituto de Letras/UFRGS, Bacharel em Direito, Mestranda em Direito/UFRGS}

Relatório:

Dados sobre a decisão: JAPÃO

- Identificação do processo: Sentença estrangeira contestada n. 6.399-0/

- Tribunal: TRIBUNAL PLENO DO SUPREMO TRIBUNAL FEDERAL;

- Data de julgamento: 21 de junho de 2000;

Japão

- Objeto: Homologação do ato administrativo que determinou o divórcio no

- Decisão: Homologação da sentença estrangeira por unanimidade de votos

Resumo do conflito e das alegações:

Os requerentes, ambos de nacionalidade brasileira, e casados entre si no Brasil, por não estarem mais interessados em manter o estado matrimonial, alcançaram, no Cartório de Registro Civil do Distrito de Itabashi, Tóquio, Japão, o divórcio, amigavelmente, através do requerimento formulado ao Chefe do Executivo local, mediante ato administrativo, conforme manda a legislação japonesa. Havendo necessidade de regularizar a situação civil junto a justiça brasileira, as partes encaminharam o pedido de homologação da decisão pelo Supremo Tribunal Federal, já que a legislação brasileira assim o exige para validar decisões estrangeiras no território nacional.

\footnotetext{
1 Trabalho final de avaliação das disciplinas da Especialização, Direito Internacional Privado, 2002. "o novo direito internacional"
} 


\section{Comentário de Decisão Homologaação do Ato Adm. - Sentença Estranģeira}

Os autos foram encaminhados ao STF e aberta vista à Procuradoria Geral da República, esta opinou pela intimação dos requerentes para que juntem aos autos o certificado de divórcio com devida chancela consular e tradução para fins de homologação porque as partes haviam juntado apenas uma certidão de registro civil.

As partes pronunciaram alegando que o requerimento do divórcio naquele país se faz mediante Poder Executivo e, portanto, impossibilitados de apresentarem tal documento solicitado. A Procuradoria, então, pronunciou-se contra a homologação por não atender os requisitos legais, quanto a sua homologabilidade, estabelecidos pelo Regimento Interno do STF, nos seus artigos 216 e 217. Os autos foram conclusos ao Tribunal Pleno, em 17 de maio de 2000.

Normas legais citadas. Base citada ou aplicável de DIP

- Artigo 102, inciso I, alínea "h" da Constituição Federal ${ }^{2}$

- Lei de Introdução ao Código Civil, artigo 7º, caput $^{3}$

- Regimento Interno do STF, artigo $215^{4}$

- Regimento Interno do STF, artigo 217, inciso I ${ }^{5}$

- Regimento Interno do STF, artigo $218^{6}$

- Jurisprudências citadas:

- Homologação de Sentença Estrangeira n.1.282/Noruega, homologada em 30 de maio de 1952, Presidente Ministro Mário Guimarães;

- Sentença Estrangeira n.1.312/Japão, Relator Ministro Mário Guimarães, 1953;

- Sentença Estrangeira n.1.943/Dinamarca, Relator Ministro Adaucto Cardoso, 1967

- Sentença Estrangeira n.2.251/Japão, Relator Ministro Moreira Alves,1975;

- Sentença Estrangeira n.2.626-1/Bélgica, Presidente Ministro Antoniọ Neder 1979

- Sentença Estrangeira n.2.891-3/Japão, Presidente Ministro Xavier de Albuquerque,1981;

- Sentença Estrangeira n.3.298, 3.371 e 3.372, todas do Japão, Presidente Ministro Cordeiro Guerra;

- Sentença Estrangeira n.3.724/Japão, Presidente Ministro Moreira Alves,1986.

\footnotetext{
${ }^{2}$ Artigo 102, inciso I, alínea " $\mathrm{h}$ " da Constituição Federal - "(...)compete ao supremo Tribunal Federal processar e julgar, originariamente, a homologação das sentenças estrangeiras(...)"(grifo nosso).

${ }^{3}$ Lei de Introdução ao Código Civil, artigo $7^{\circ}$, caput - "A lei do pais em que for domiciliada a pessoa determina as regras sobre o começo e o fim da personalidade, o nome, a capacidade e os direitos de familia."

"Regimento Interno do STF, artigo 215 - "A sentença estrangeira não terá eficácia no Brasil sem prévia homologação pelo Supremo Tribunal Federal ou por seu Presidente.

${ }^{5}$ Regimento Interno do STF, artigo 217, inciso I- "Constituem requisitos indispensáveis à homologação da sentença estrangeira: I - haver sido proferida por juiz competente."

${ }^{6}$ Regimento Interno do STF, artigo 218 - "A homologação será requerida pela parte interessada (...) e ser instruída com a certidão ou cópia autêntica do texto integral da sentença estrangeira e com outros documentos indispensáveis, devidamente traduzidos e autenticados."
} 


\section{Resumo do decisum}

Após pronunciamento da Procuradoria Geral da República, contra a homologação, os autos vieram conclusos ao Tribunal Pleno do STF, em 17 de maio de 2000. Em 22 de junho, contrariando a posição da Procuradoria, é deferido pelo Tribunal Pleno o pedido formulado com homologação do ato mediante o qual os requerentes alcançaram o divórcio. Justificando que o vício apontado pela Procuradoria Geral, ou seja, a falta da sentença não é impeditória à homologação eis que o divórcio fora efetuada no Japão com plena observância das normas de regência aplicáveis à espécie, e mesmo que a quisessem, não poderiam, naquele país, obter a sentença.

Tendo o divórcio alcançado no Japão, a envergadura de sentença segundo a legislação de origem, os Ministros, em sessão plenária, por unanimidade de votos, homologaram o ato administrativo de divórcio equiparando-o à sentença estrangeira. Ressavando, ainda, que o ato foi realizado em janeiro de 2000, quando já vigorava a legislação que regula o divórcio no Brasil.

\section{Análise da Decisão}

1- Elementos de conexão:

Primeiramente, devemos analisar elemento de conexão que caracteriza o DIP. No caso citado acima, o primeiro elemento de conexão utilizada para exigência da homologação foi o divórcio realizado no país estrangeiro segundo legislação estrangeira. O divórcio alterou o estado civil dos requerentes no Japão. Porém, para ser eficaz o tal ato no território nacional, se faz indispensável a sua homologação conforme estabelece artigo 215 do Regimento Interno do $\mathrm{STF}^{7}$, daí a necessidade de tal requerimento. $\mathrm{O}$ segundo elemento de conexão a ser analisado, ao meu ver, é a própria validade do ato do divórcio segundo as normas do Direito Internacional Privado. O artigo $7 \stackrel{\circ}{*}$ da Lei de Introdução ao Código Civil de 4 de setembro de 1942 diz:

"A lei do país em que for domiciliada a pessoa determina as regras sobre o começo e o fim da personalidade, o nome, a capacidade e os direitos de família."

. Já o Código Bustamante de 1928 promulgado no Brasil pelo Decreto n. 18.871 em 1929, em seu Capítulo IV, Seção V, que trata "da separação de corpos e do divórcio", artigo 52 dizia:

"O direito à separação de corpos e ao divórcio regula-se pela lei do domicílio conjugal, mas não se pode fundar em causas anteriores à aquisição do dito domicílio se as não autorizar, com iguais efeitos, a lei pessoal de ambos os cônjuges"

Portanto, segundo a legislação brasileira, aplica-se o princípio da territorialidade ratione loci, no que tange ao direito de família, inclusive o divórcio. Ora, in casu, aplicouse a legislação japonesa eis que os requerentes mantinham seus domicílios no Japão, ato plenamente válido segundo nossas normas de DIP.

${ }^{7}$ STRENGER, Irineu, Direitos e obrigações dos estrangeiros no Brasil. São Paulo: LTr, 1997, p.52. 
A aplicação da legislação daquele país realizou-se segundo os princípios das normas de aplicação imediata no Direito Internacional Privado. A. M. Santos, na sua introdução do livro "As normas de aplicação imediata no Direito Internacional Privado" afirma que a regra de aplicação imediata do direito interno como uma das categorias das normas de DIP, ao lado das regras de DIP material e das regras conflito de leis ${ }^{8}$. A legislação brasileira, através da LICC, art. $7^{\circ}$ manda aplicar diretamente a lei estrangeira no que tange a direito pessoal às pessoas físicas domiciliados no estrangeiro seguindo o princípio da territorialidade.

O que ocorreu aqui foi a utilização do foro estrangeiro para aplicação da lei, ou seja, a lei que regulamenta o divórcio, prevista conforme legislação citada acima. Portanto, tal ato não fere a soberania do Estado nacional, sendo sua decisão passível de ser homologada no Brasil.

\section{2 - Princípio aplicado:}

Outro elemento que deve ser analisada é o princípio de ordem pública. $\bigcirc$ artigo $5^{\circ}$ da Lei de Introdução ao Código Civil diz que "na aplicação da lei, o juiz atenderá aos fins sociais a que ela se dirige e às exigências do bem comum". O Brasil atualmente reconhece a figura do divórcio através da lei n.6515/77. Se não existisse tal legislação, o seu divórcio não poderia ser reconhecido sobremaneira dos requerentes que têm nacionalidades brasileiras ${ }^{9}$. $\bigcirc$ fim social da lei constitui o critério positivo da determinação do elemento de conexão decisivo da lei normalmente competente para regular relações jurídicas.

Verificada a inexistência da violação do princípio de ordem pública e alcançado o fim social almejada, é perfeitamente aplicável a legislação japonesa ${ }^{10}$ ao ato do divórcio.

Entretanto, ao meu ver, o Tribunal Pleno preocupou-se, basicamente quanto a formalidade em reconhecer o ato administrativo que determinou o divórcio, equiparando-o a sentença judicial, efetuando a harmonização fazendo valer-se o direito do país com o qual a relação jurídica tem conexão internacional. A homologação proferida por Tribunal baseou-se na interpretação analógica equiparando ato administrativo que decretou o divórcio à sentença judicial visto que esta forma inexiste no país de origem mas que alcança objetivo comum que é o divórcio. A fundamentação do acórdão é dada mediante apresentação de jurisprudências enumeradas na Segunda

${ }^{8}$ SANTOS, António Marques dos, As normas de aplicação imediata no direito internacional privado: esboço de uma teoria geral. Coimbra: Amedina, 1991, p 7-8.

${ }^{9}$ SANTOS, António Marques dos, As normas de aplicação imediata no direito internacional privado: esboço de uma teoria geral. Coimbra: Amedina, 1991, v.2, p 719-720 - " (...) ${ }^{\text {a Machado }}$ Villela parte da noção savigniana de leis de natureza positiva rigorosamente obrigatórias e entende que tal noção foi assimilada pela escola personalista italiana, que lhe deu, porém, Fusinato e de P. Fiore, os quais (...) punham a ênfase; respectivamente, nos direitos e interesses
supremos do Estado, na antinomia do conteúdo das leis estrangeiras relativamente ao da lei do foro(...), ou no caráter particularmente imperativo. ; AMORIM, Edgar Carlos de. Direito internacional privado. Rio de Janeiro: Forense, 1997, 3 ed. p 135-136; RECHSTEINER, Beat Waiter, Direito internacional privado, teoria e prática. Säo Paulo: Editora Saraiva, 1996, p.10-13.

10 SANTOS, António Marques dos, ibidem, p. 1067. 
parte do presente trabalho. Ao preservar o direito resguardado pelo direito de família brasileira, mais especificamente, o resguardado pela Lei 6515 de 1977 onde é regulado o divórcio, percebe-se que os Exmos. Ministros adotou o princípio de ordem pública..

Esta posição do tribunal que homologou a decisão administiva equiparando-a a sentença judicial, alcançou, ao meu ver, o fim almejado, apesar de, aparentemen-te, não usar os conhecimentos atuais do Direito Internacional como poderia ser.

\section{Conclusão}

O decisum alcançou a solução da divergência da formalidade legal que envolve o ato decisório que estabelece o divórcio que é divergente entre legislação japonesa e brasileira. Aquela manda realizar o divórcio amigável mediante ato administrativo pelo executivo local ao passo que o último exige a presença do poder judiciário para tratar decidir sobre tal matéria. Ao recorrer à harmonização e acatando a decisão administrativa estrangeira como sentença judicial, possibilitou a sua homologação e com isso, o fim foi alcançado sem prejuízo das partes, naõ impondo quaisquer restrição visto que o fato deu-se em janeiro de 2000, quando a lei do divórcio já estava em pleno vigor não deixando nenhuma dúvida quanto ao seu mérito.

\section{Bibliografia}

- AMORIM, Edgar Carlos de. Direito internacional privado. Rio de Janeiro: Forense, 1997, 3 ed.;

- BAPTISTA, Luiz Olavo et alii org., Normas de direito internacionali: tomo II: direito internacional da pessoa. São Paulo: LTr, 2000, v. 2; 995,5 ed.;

- CASTRO, Amílcar de, Direito internacional privado. Rio de Janeiro: Forense,

- RECHSTEINER, Beat Walter, Direito internacional privado, teoria e prática. São Paulo: Editora Saraiva, 1996;

- SANTOS, António Marques dos, As normas de aplicação imediata no direito internacional privado: esboço de uma teoria geral. Coimbra: Amedina, 1991,

- v.1 e v.2;

- STRENGER, Irineu, Direitos e obrigações dos estrangeiros no Brasil. São Paulo: LTr, 1997. 
$21 / 06 / 2000$

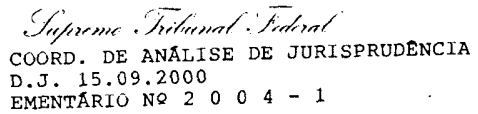

RELATOR : MIN. MARCO AURÉLIO

REQUERENTE: OSVALDO MASAKAZU KITAHARA OU MASAKAZU KITAHARA

REQUERENTE: NILVA SHIZUCO YAMACHI OU NILVA SHIZUCO KITAHARA OU SHIZUKO KITAHARA

ADVOGADOS: CARLOS ALBERTO DE OLIVEIRA CAVALCANTI E OUTROS REQUERIDOS: OS MESMOS

SENTENÇA ESTRANGEIRA - HOMOLOGAÇÃO - DIVÓRCIO - ATO ADMINISTRATIVO - EXTENSÃO. A norma inserta na alínea " $\mathrm{h}$ " do inciso I do artigo 102 da Constituicao Federal, segundo a qual compete ao Supremo Tribunal Federal processar e julgar, originariamente, a homologação das sentenças estrangeiras, há de ser tomada respeitando-se a soberania do país em que praticado o ato. Prevendo a respectiva legislação o divórcio mediante simples ato administrativo, como ocorre, por exemplo, no Japão, cabível é a homologação para que surta efeitos no território brasileiro. Precedentes: Sentença Estrangeira $n^{\circ} 1.282 /$ Noruega, Relator Ministro

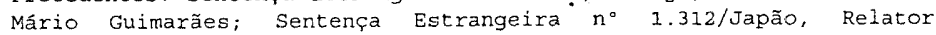
Ministro Mário Guimarães; Sentença Estrangeira n 1.943/Dinamarca, Relator Ministro Adaucto Cardoso; Sentença Estrangeira $n^{\circ}$ 2.251/Japão, Relator Ministro Moreira Alves; Sentença Estrangeira $n^{\circ}$ 2.626/Bélgica, Presidente Ministro Antonio Neder; Sentença

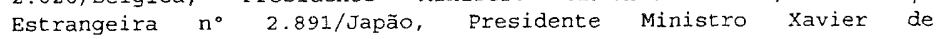
Albuquerque; Sentenças Estrangeiras $n^{\circ} \mathrm{s} 3.298,3.371$ e 3.372 , todas do Japão, Presidente Ministro Cordeiro Guerra; e Sentença

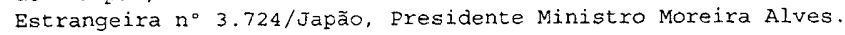

$\underline{A} \subseteq \underline{O} \underline{R} \underline{\mathrm{D}} \underline{\tilde{\mathrm{O}}} \underline{O}$

Vistos, relatados e discutidos estes autos, acordam os Ministros do supremo Tribunal Federal, em sessão plenárią, na 


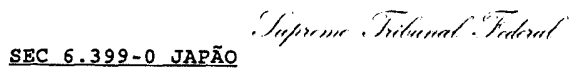

conformidade da ata do julgamento e das notas taquigráficas, por unanimidade de votos, em homologar a sentença estrangeira.

Brasília, 21 de junho de 2000 .

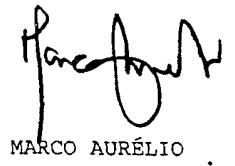

RELATOR 


\title{
SENTENCA ESTRANGEIRA CONTESTADA N. 6.399-0 JAPÃO
}

RELATOR : MIN. MARCO AURÉLIO

REQUERENTE: OSVALDO MASAKAZU KITAHARA OU MASAKAZU KITAHARA

REQUERENTE: NILVA SHIZUCO YAMACHI OU NILVA SHIZUCO KITAHARA OU SHIZUKO KITAHARA

ADVOGADOS: CARLOS ALBERTO DE OLIVEIRA CAVALCANTI E OUTROS REQUERIDOS : OS MESMOS

\author{
$\underline{R} \underline{\underline{E}} \underline{\mathrm{A}} \underline{\mathrm{T}} \underline{\mathrm{O}} \underline{\underline{I}} \underline{\mathrm{S}}$
}

- SENHOR MINISTRO MARCo AURÉLIO - Na inicial de folha

2 à 4, veiculou-se pedido de homologação, com base na legislação de regência, de ato mediante $\circ$ qual os Requerentes alcançaram, no Cartório de Registro Civil do Distrito de Itabashi, Tóquio, Japão, o divôrcio. Apontaram a necessidade de regularizarem a situação civil junto à Justiça brasileira. Com a peça, vieram os documentos de folha 5 à 10 .

À folha 14, O titular da Presidência, Ministro Carlos Velloso, abriu vista à Procuradoria Geral da Repúbliea, pronunciando-se esta à folha 16 :

(...) pela intimação dos requerentes para que juntem aos autos o certificado de divórcio, com a devida chancela consular e tradução oficial, pois 0 documento de fls. 6, traduzido às fls. 7/8, é ppenas 


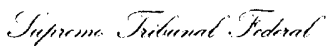

SEC 6.399-0 JAPÃO

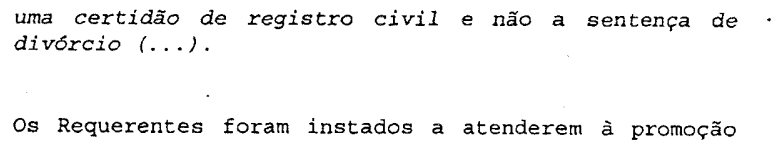




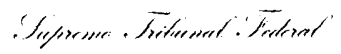

SEC $6.399-0$ JAPÃO

$\underline{\mathrm{V}} \underline{\mathrm{I}} \underline{\mathrm{O}}$

\section{- SENhor MINISTRO MARCO AURËLIO (RELATOR) - Na} espécie, cuida-se de divórcio amigável, havendo ocorrido a juntada, à inicial, da certidão de casamento dos Requerentes em solo brasileiro (folha 10), bem como do registro no Japão e posterior divórcio mediante ato administrativo, como dispõe a legislação do país de origem. A peça original noticiadora destes últimos acontecimentos veio aos autos com a charrcela do Consulado Geral da República Federativa do Brasil em Tóquio (folha 6-verso). o vício apontado pela Procuradoria Geral da República está ligado ao meio pelo qual foi alcançado o divórcio, cujas balizas não são as da legislação brasileira, mas as do país em que formalizado. É certo prever o artigo 102, inciso I, alínea "h", da Constituição Federal a competência do supremo Tribunal Federal para processar e julgar, originariamente, a homologação das sentenças estrangeiras. Todavia, há de adotar-se interpretação aditiva, vislumbrando-se, na referência a sentenças estrangeiras, documentos que, segundo a legislação de origem, tenham tal envergadura. É o caso do ato administrativo de divórcio. No Japão, não é alcançado o defseplace 


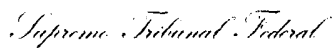

SEC 6.399-0 JAPÃO

matrimonial via sentença, mas mediante o registro no cartório competente, atuando o administrador do distrito. Foi justamente o que ocorreu na espécie dos autos, conforme revelam as peças de folha 7 à 9. Em sintese, os Requerentes, com plena observância das normas de regência aplicáveis à espécie, lograram, no Japão, o divórcio, e, mesmo que quisessem, não poderiam, naquele pais, obtex o que exigido pela Procuradoria Geral da República.

- tema não é novo. Esta Corte, ao defrontar-se com o pedido de homologação da Sentença Estrangeira $\mathrm{n}^{\circ} 1.282$, origináxia da Noruega, proclamou, mediante acórdăo redigido pelo Ministro Mário Guimarães :

Homologa-se o divorcio se foi feico com as
formalidades de seu paŕs de origem.
Homologação de divorcio por decisão de
autoridade administrativa.
Efeitos, sendo un dos cônjuges de
nacionalidade brasileira.

Na oportunidade, em 30 de maio de 1952, pronunciaramse os Ministros, a uma só voz, pela viabilidade da homologação, fazendo-o de forma fundamentada não só o Relator, como tambề os Ministros Abner de Vasconcelos, Luiz Gallotti e Orosimbo Nonato. Em 1953. - Plenário veio a enfrentar situação na qual envolvid@ ato originário do Japão. Mais uma vez, proclamou-se: 


\section{Sigierme Srituenet Frdent}

SEC $6.399-0$ JAPÃO

Homologa-se o divórcio amigável registrado, no Japão, pelo Prefeito Municipal - A lei desse país reconhece como legal o divórcio processado nessas condições (Sentença Estrangeira $n^{\circ} 1.312$ ).

Funcionou como Relator o Ministro Mário Guimarães. Em 1967, voltou o Tribunal a examinar a matéria, fazendo-o quanto ao que previsto na Dinamarca. Mais uma vez, procedeu à homologação, assim ficando sintetizada a ementa do acórdão:

SENTENÇA ESTRANGEIRA DE DIVÓRCIO DE CIDADÃOS DINAMARQUESES. Homologaçăo: Satisfeitas as exigências legais, é de ser homologada para todos os efeitos.

A citada sentença decorrera de ato do próprio Rei da Dinamarca - Sentença Estrangeira n० 1.943, Relator Ministro Adaucto Cardoso. Em 1975, veio a ser homologada a Sentença Estrangeira $n^{\circ}$ 2.251, também originária do Japão, como a que se encontra em mesa, sintetizando o Ministro Moreira Alves a tese prevalecente:

Divórcio. E homologável no Brasil divórcio por mútuo consentimento que, segundo o sistema jurídico japonês, se registra perante autoridade administrativa, independentemente de manifestação judicial. Precedente do S.T.F. Homologação com restricões, em face da nacionalidade brasileira of uma das partes. 


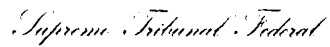

SEC $6.399-0$ JAPÃO

Seguiram-se homologações pela Presidencia: Sentença Estrangeira $n^{\circ}$ 2.626-1/Bélgica, homologação em 26 de outubro de 1979, Presidente Ministro Antonio Neder; Sentença Estrangeira n 2.891-3/Japão, homologạão em 19 de março de 1981, pelo presidente Ministro Xavier de Albuquerque; Sentença Estrangeira $n^{\circ} 3.298$ 8/Japão, homologação em 16 de setembro de 1983 , pelo presidente Cordeiro Guerra. Em 19 de março de 1984, Sua Excelência homologou as Sentenças Estrangeiras, originárias do Japão, de $\mathrm{n}^{\circ} \mathrm{s} 3.371-2$ e $3.37 \bar{z}-t$, sendo que o Ministro Moreira Alves, na Presidência da Corte em 2 de julho de 1986, procedeu à homologação da de $n^{\circ} 3.724-6$, também originária do Japão.

Destarte, a optica da procuradoria Geral da Repüblica distancia-se dos citados precedentes, no que potencializa a alusão, na Carta Federal, à homologação de sentenças.

Defiro o pedido formulado e homologo, para que surta eficácia no Brasil, 0 ato mediante 0 qual os Requerentes divorciaram-se, não impondo qualquer restrição, porquanto 0 fato deu-se em janeiro último, e, portanto, quando admitido, no Brasil, o divórcio. Aliás, não ocorresse isso, seria o caso de emprestar-se ao ato, porquanto brasileiros ambos os Requerentes, o alcance pródrfo à separação judicial. 
PLENÁRTO

\section{EXTRATO DE ATA}

SENTENCYA ESTRANGEIRA CONTESTADA N. 6.399-0

PROCED. : JAPÃO

RELATOR : MIN. MARCO AURÉEIO

REQTE, : OSVALDO MASAKAZU KITAHARA OU MASAKAZU KITAHARA

REQTE. : NILVA SHIZUCO YAMACHI OU NILVA SHIZUCO KITAHARA OU SHIZUKO KITAHARA

ADVDOS. : CARLOS ALBERTO DE OLIVEIRA CAVALCANTI E OUTROS

REQDOS. : OS MESMOS

Decisão : O Tribunal, por unanimidade, homologou a

sentença estrangeira. Ausentes, justificadamente, os senhores Ministros Moreira Alves e Celso de Mello, e, neste julgamento, o Senhor Ministro Sydney Sanches. Plenário, 21.6.2000.

Presidência do Senhor Ministro carlos velloso. presentes à sessão os Senhores Ministros Néri da Silveira, sydney Sanches, octavio Gallotti, Sepúlveda Pertence, Marco Aurélio, Ilmar Galvão, Maurício Corrêa e Nelson Jobim.

Procurador-Geral da República, Dr. Geraldo Brindeiro.

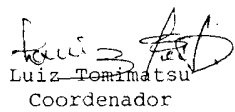

